\title{
Article \\ Diet-Related Phototoxic Reactions in Psoriatic Patients Undergoing Phototherapy: Results from a Multicenter Prospective Study
}

\author{
Alessia Pacifico ${ }^{1}$, Rosalynn R. Z. Conic ${ }^{2}{ }^{(D}$, Antonio Cristaudo ${ }^{1}$, Sergio Garbarino ${ }^{3}\left(\mathbb{D}\right.$, Marco Ardigò $^{1}$, \\ Aldo Morrone ${ }^{1}$, Paolo Iacovelli ${ }^{1}$, Sara di Gregorio ${ }^{4}$, Paolo Daniele Maria Pigatto ${ }^{4,5}$, Ayman Grada 6 (D), \\ Steven Richard Feldman ${ }^{7}$ (D), Egeria Scoditti ${ }^{8}$ (D), Khalaf Kridin ${ }^{9,+}$ and Giovanni Damiani ${ }^{4,5,10, *,+}+\mathbb{D}$
}

\section{check for} updates

Citation: Pacifico, A.; Conic, R.R.Z; Cristaudo, A.; Garbarino, S.; Ardigò,

M.; Morrone, A.; Iacovelli, P.; di Gregorio, S.; Pigatto, P.D.M.; Grada, A.; et al. Diet-Related Phototoxic Reactions in Psoriatic Patients Undergoing Phototherapy: Results from a Multicenter Prospective Study. Nutrients 2021, 13, 2934. https:// doi.org/10.3390/nu13092934

Academic Editor: Winston Craig

Received: 18 July 2021

Accepted: 19 August 2021

Published: 25 August 2021

Publisher's Note: MDPI stays neutral with regard to jurisdictional claims in published maps and institutional affiliations.

Copyright: (c) 2021 by the authors. Licensee MDPI, Basel, Switzerland. This article is an open access article distributed under the terms and conditions of the Creative Commons Attribution (CC BY) license (https:// creativecommons.org/licenses/by/ $4.0 /)$.
1 Clinical Dermatology Department, San Gallicano Dermatological Institute, IRCCS, 00144 Rome, Italy; alessia.pacifico@gmail.com (A.P.); antonio.cristaudo@libero.it (A.C.); ardigo.marco@gmail.com (M.A.); aldomorrone54@gmail.com (A.M.); paolo.iacovelli@ifo.gov.it (P.I.)

2 Department of Preventive Medicine, Maryland University, Baltimore, MD 21201, USA; ruzica.conic@gmail.com

3 Department of Neuroscience, Rehabilitation, Ophthalmology, Genetics and Maternal/Child Sciences, Polyclinic Hospital San Martino Istituto di Ricovero e Cura a Carattere Scientifico (IRCCS), University of Genoa, 16132 Genoa, Italy; sgarbarino.neuro@gmail.com

4 Clinical Dermatology, IRCCS Istituto Ortopedico Galeazzi, 20161 Milan, Italy; saradigregorio95@gmail.com (S.d.G.); paolo.pigatto@unimi.it (P.D.M.P.)

5 Department of Biomedical, Surgical and Dental Sciences, University of Milan, 20122 Milan, Italy

6 Department of Dermatology, Boston University School of Medicine, Boston, MA 02118, USA; grada@bu.edu

7 Wake Forest School of Medicine, Department of Dermatology, Winston-Salem, NC 27157, USA; sfeldman@wakehealth.edu

8 Institute of Clinical Physiology, National Research Council (CNR), 73100 Lecce, Italy; egeria.scoditti@ifc.cnr.it

9 Lübeck Institute of Experimental Dermatology, University of Lübeck, 23538 Lübeck, Germany; dr_kridin@hotmail.com

10 PhD Degree Program in Pharmacological Sciences, Department of Pharmaceutical and Pharmacological Sciences, University of Padua, 35131 Padua, Italy

* Correspondence: dr.giovanni.damiani@gmail.com; Tel.: +39-02-662141

$\dagger \quad$ These authors contributed equally to this work.

Abstract: Vegans and vegetarians often consume foods containing photosensitizers capable of triggering phytophotodermatitis. The potential effect of vegan and vegetarian diets on the response of psoriatic patients undergoing phototherapy is not well characterized. We assessed clinical outcomes of vegan, vegetarian and omnivore adult psoriatic patients undergoing band ultraviolet $B$ phototherapy (NB-UVB). In this multicenter prospective observational study, we enrolled 119 adult, psoriatic patients, of whom 40 were omnivores, 41 were vegetarians and 38 were vegans, with phototherapy indication. After determining the minimum erythemal dose (MED), we performed NB-UVB sessions for 8 weeks. The first irradiation dosage was $70.00 \%$ of the MED, then increased by $20.00 \%$ (no erythema) or by $10.00 \%$ (presence of erythema) until a maximum single dose of $3 \mathrm{~J} / \mathrm{cm}^{2}$ was reached and constantly maintained. All the enrolled patients completed the 8 weeks of therapy. Severe erythema was present in $16(42.11 \%)$ vegans, $7(17.07 \%)$ vegetarians and $4(10.00 \%)$ omnivores $(p<0.01)$. MED was lowest among vegans $\left(21.18 \pm 4.85 \mathrm{~J} / \mathrm{m}^{2}\right)$, followed by vegetarians $\left(28.90 \pm 6.66 \mathrm{~J} / \mathrm{m}^{2}\right)$ and omnivores $\left(33.63 \pm 4.53 \mathrm{~J} / \mathrm{m}^{2}, p<0.01\right)$. Patients with severe erythema were more likely to have a high furocumarin intake (OR 5.67, 95\% CI 3.74-8.61, $p<0.01$ ). Vegans consumed the highest amount of furocumarin-rich foods. A model examining erythema, adjusted for gender, age, skin type, MED, phototherapy type, number of phototherapies and furocumarin intake, confirmed that vegans had a lower number of treatments. Vegans had more frequent severe erythema from NB-UVB, even after adjustment of the phototherapy protocol for their lower MED. Assessing diet information and adapting the protocol for vegan patients may be prudent.

Keywords: psoriasis; diet; vegans; vegetarians; omnivores; phototherapy; NB-UVB; efficacy; precision medicine; exposures; exposome; inflammation 


\section{Introduction}

For more than a decade, psoriasis has been considered as a systemic, inflammatory disease with cutaneous [1,2] and musculoskeletal manifestations [3] enriched by a wide range of comorbidities [4], ranging from respiratory [5-8] to cardiometabolic ones $[9,10]$.

While obesity and metabolic syndrome are risk factors for psoriasis, the contribution of diet to psoriasis and its treatment outcomes are still not completely defined [11]. Vegans and vegetarians often consume vegetables containing furocumarins (i.e., celery, parsnip, carrot, parsley, citrus and figs), natural photosensitizers and triggers for phytophotodermatitis in both humans and animals [12-18]. Furocumarins are characterized by a coumarin structure with a furan ring and are traditionally classified into linear ("psoralen type") and angular ("angelicin type") types [19]. Furocumarins are well absorbed from food sources and rapidly distributed into several tissues, including skin [19], so phototoxic reactions due to the ingestion of food containing such photosensitizers can occur [20].

Narrow-band ultraviolet B phototherapy (NB-UVB) represents a useful pre-biologics therapeutic option for psoriatic patients [21]. NB-UVB phototherapy may induce psoriasis clearance through pleiotropic effects on human cutaneous immunity, including the activation of apoptosis, DNA damage response and repair pathways, cell cycle control/differentiation and inflammation regulation [22]. Circadian rhythmicity disruption is also involved in psoriasis pathophysiology [23] and may influence NB-UVB response $[22,24,25]$. Furthermore, the concept that diet influences both inflammation and peripheral clocks is well established $[16,17,26,27]$, but the impact of vegan and vegetarian diets on phototherapy remains neglected. Due to the increasing number of vegetarians and vegans in the general population, we explored the effect of these diets in psoriatic patients undergoing NB-UVB.

\section{Materials and Methods}

\subsection{Study Design}

This was a multicenter prospective observational study involving two primary referral phototherapy centers (IRCCS San Gallicano Hospital-Rome, and IRCCS Istituto Ortopedico Galeazzi-Milan, Italy). Patients fulfilling inclusion criteria were enrolled, evaluated (T0) and followed up for 8 weeks (T1). Vegans, vegetarians and omnivores were matched for age, gender, skin phenotype and Psoriasis Area Severity Index (PASI). Saint Rafael Hospital (OSR) local ethical committee approved in 28 May 2021 the study protocol 176/int/2020 and the current study represents a post-hoc analysis. Each patient signed an written informed consent.

\subsection{Inclusion/Exclusion Criteria}

We enrolled adult patients ( $\geq 18$ years) with plaque psoriasis and Fitzpatrick skin type II-IV with an indication for NB-UVB phototherapy. Psoriatic erythroderma was excluded because it is an absolute contraindication to phototherapy. Patients with psoriatic arthritis that refuse systemic treatments but underwent NB-UVB were included.

Conversely, patients were excluded in case of (a) previous history of skin cancer or chemotherapy ( $<5$ years before); (b) ongoing therapies potentially aggravating psoriasis or recognized as photosensitizing; (c) undergoing topical anti-psoriatic treatments in the previous 2 weeks or systemic ones in the previous 4 weeks; or (d) acute or chronic infectious comorbidities.

\subsection{MED Evaluation and Erythema Quantification}

MED testing was performed on normal dorsal skin of each enrolled patient before starting phototherapy using a Multiport UV Solar Simulator 601 (Solar Light CO.INC: Philadelphia, PA, USA) [28]. MED testing was repeated after 8 weeks of phototherapy treatment to evaluate photoadaptation. Before and after the phototherapy course, each 
patient was evaluated for the erythema index with a skin reflectance measuring instrument (Mexameter MX16, Courage \& Khazaka Electronics, Cologne, Germany).

MED was calculated more than 6 hours after the last meal to prevent furocumarins absorption peak [19].

\subsection{Phototherapy Protocol}

NB-UVB was delivered by a PUVA Combi Light PCL 8000 phototherapy booth (Heverlee, Belgium) equipped with 48 Phillips ${ }^{\circledR}$ TL100 W/01 tubes in both centers, and both used the same dosimeter. The fluence in the center was $15 \mathrm{~mW} / \mathrm{cm}^{2}$, as measured with a Waldmann Variocontrol dosimeter (WaldmannMedizintechnik $\mathrm{GmbH}$, Villingen-Schwenningen, Germany). The initial irradiation dose was chosen based on a subject's minimal erythema dose (MED).

The first irradiation dosage was $70.00 \%$ of the MED, which was then increased by $20.00 \%$ (in the absence of erythema) or by $10 \%$ (in case of a minimal perceptible onset erythema) until a maximum single dose of $3.00 \mathrm{~J} / \mathrm{cm}^{2}$ was reached, after which the dose was constantly maintained. Irradiations were administered three times weekly for up to 8 weeks. In the case of patients susceptible to develop a severe erythema, dosing was reduced to two treatments per week.

\subsection{Dietary Evaluation}

During the dermatological visit, dietary information was recorded and patients were classified as vegans, vegetarians or omnivores using the following definitions:

- Vegans where patients "ate only all kinds of fruits, vegetables, nuts, grains, seeds, beans and pulses" [29];

- Vegetarians or "fully vegetarians" where patients "never ate meat, poultry and fish, or ate these foods less than once a month" [30];

- Omnivores if they patients not represented by the previous classifications.

We asked patients to list and weigh each food they consumed in a diet diary for a week. From this information, we identified the approximative quantities of polyphenols [31], carotenoids [32], astaxanthins [33] and furocumarins [34] consumed using converting tables already present in the literature. Then, we divided the obtained quantitatives for each evaluated substance into tertiles and named the first tertile as "low" "none" in case of no intake), the second one as "intermediate" and the third one as "high" consumption.

\subsection{Statistical Analysis}

Demographic and food intake characteristics between omnivores, vegetarians and vegans were compared using the $t$-test for continuous variables and the chi-square test for categorical variables. Association between erythema and diet was further examined using a linear regression adjusting for gender, age, skin type, MED, phototherapy type, number of therapies and furocumarin use.

\section{Results}

\subsection{Clinical Data and Demographics}

We enrolled 119 psoriatic patients (40 omnivores, 41 vegetarians and 38 vegans) and all of them completed the 8 weeks of therapy. There were no differences in gender $(p=0.68)$, age $(p=0.79)$, skin type $(p=0.43)$, number of phototherapy treatments $(0.40)$ or baseline (T0) PASI $(p=0.55)$.

Remarkably, after 8 weeks of NB-UVB, there was a statistically significant difference in PASI between omnivores, vegans and vegetarians (1.95 vs. 8.87 vs. $4.59, p<0.01)$ (Table 1$)$. 
Table 1. Socio-demographic and clinical characteristics of omnivores, vegetarians and vegans.

\begin{tabular}{|c|c|c|c|c|}
\hline Population Characteristics & $\begin{array}{c}\text { Omnivores } \\
(n=40)\end{array}$ & $\begin{array}{l}\text { Vegans } \\
(n=38)\end{array}$ & $\begin{array}{l}\text { Vegetarians } \\
\quad(n=41)\end{array}$ & $p$ \\
\hline Male, $n(\%)$ & $19(47.50)$ & $18(47.37)$ & $16(39.02)$ & 0.68 \\
\hline \multicolumn{5}{|l|}{ Skin Phototypes } \\
\hline II & $4(10.00)$ & $9(23.68)$ & $8(19.51)$ & \multirow{4}{*}{0.43} \\
\hline III & $17(42.50)$ & $16(42.11)$ & $19(46.34)$ & \\
\hline IV & $19(47.50)$ & $12(31.58)$ & $14(34.15)$ & \\
\hline $\mathrm{V}$ & $0(0.00)$ & $1(2.63)$ & $0(0.0))$ & \\
\hline Age (average (SD), years) & $39.27(9.24)$ & $40.66(8.28)$ & $39.80(8.96)$ & 0.79 \\
\hline \multicolumn{5}{|l|}{ PASI (average (SD)) } \\
\hline T0 & $12.78(2.83)$ & $12.39(2.95)$ & $13.15(3.27)$ & \multirow{2}{*}{$\begin{array}{c}0.55 \\
<0.01\end{array}$} \\
\hline $\mathrm{T} 1$ & $1.95(4.09)$ & $8.87(4.31)$ & $4.59(5.24)$ & \\
\hline MED (average (SD), $\mathrm{mJ} / \mathrm{cm}^{2}$ ) & $33.62(4.53)$ & $21.18(4.85)$ & $28.90(6.66)$ & $<0.01$ \\
\hline Treatments (average (SD) & $15.07(4.28)$ & $12.13(6.41)$ & $14.61(5.38)$ & 0.40 \\
\hline \multicolumn{5}{|l|}{ Erythema (\%) } \\
\hline Absent & $19(47.50)$ & $0(0.00)$ & $14(34.15)$ & \multirow{4}{*}{$<0.001$} \\
\hline Mild & $17(42.50)$ & $10(26.32)$ & $14(34.15)$ & \\
\hline Moderate & $0(0.00)$ & $12(31.58)$ & $6(14.63)$ & \\
\hline Severe & $4(10.00)$ & $16(42.11)$ & $7(17.07)$ & \\
\hline PsA, $n(\%)$ & $11(27.50)$ & $11(28.95)$ & $11(26.83)$ & 0.98 \\
\hline DAPSA (average (SD)) & 14.75 (2.99) & $16.00(2.05)$ & $12.82(2.32)$ & 0.21 \\
\hline
\end{tabular}

DAPSA: Disease Activity Index for PSoriatic Arthritis, MED: minimal erythematous dose, PASI: Psoriasis Area Severity Index, PsA: psoriatic arthritis, SD: standard deviation.

\subsection{Erythema and $M E D$}

Severe erythema was present in $16(42.11 \%)$ vegans, $7(17.07 \%)$ vegetarians and $4(10.00 \%)$ omnivores $(p<0.01)$. In total, $19(47.50 \%)$ omnivores and $14(34.15 \%)$ vegetarians experienced no erythema, whilst all vegans experienced some degree of erythema. Patients with severe erythema underwent fewer phototherapy sessions. MED was lowest among vegans $\left(21.18 \pm 4.85 \mathrm{~J} / \mathrm{m}^{2}\right)$, followed by vegetarians $\left(28.90 \pm 6.66 \mathrm{~J} / \mathrm{m}^{2}\right)$ and omnivores $\left(33.63 \pm 4.53 \mathrm{~J} / \mathrm{m}^{2}, p<0.01\right)$.

\subsection{Diet Photoactives and Their Impact}

Interestingly, $21(55.26 \%)$ vegans consumed high doses of furocumarins, followed by $4(10.00 \%)$ vegetarians and no omnivores $(p<0.01)$. Astaxanthines consumption was high in about $23(29.11 \%)$ vegans and vegetarians, but only in 1 omnivore $(p<0.01)$. High polyphenol consumption was reported by $14(36.84 \%)$ vegans, $11(26.83 \%)$ of vegetarians and only 1 omnivore $(p<0.01)$. There was no difference in carotenoid intake between vegetarians, vegans and omnivores $(p=0.31)$ (Table 2$)$. Only two omnivores consumed a high number of vegetables.

A model examining erythema, adjusted for gender, age, skin type, MED, phototherapy type, number of phototherapies and furocumarins intake, confirmed that vegans had a lower number of treatments. Patients with a high furocumarins intake displayed a 5.67-fold risk (95\% CI 3.74-8.61, $p<0.001)$ of developing erythema, followed by medium (OR 1.96 (1.52-2.53)) and low (OR 4.43 (2.93-6.71)) intakes, compared to no furocumarin intake. All the main foods rich in furocumarins consumed by our population achieved a statistically significant difference between omnivores, vegans and vegetarians (see Table 3). 
Table 2. Different intakes of the main photoactives between omnivores, vegetarians and vegans.

\begin{tabular}{|c|c|c|c|c|}
\hline $\begin{array}{l}\text { Level of Photoactives } \\
\text { Ingested }\end{array}$ & $\begin{array}{l}\text { Omnivores } \\
(N=40)\end{array}$ & $\begin{array}{l}\text { Vegans } \\
(N=38)\end{array}$ & $\begin{array}{l}\text { Vegetarians } \\
(N=41)\end{array}$ & $p$ \\
\hline \multicolumn{5}{|l|}{ Furocumarins, $N(\%)$} \\
\hline None & $29(72.50)$ & $0(0.00)$ & $14(34.15)$ & \multirow{4}{*}{$<0.01$} \\
\hline Low & $11(27.50)$ & $10(26.32)$ & $16(39.02)$ & \\
\hline Intermediate & $0(0.00)$ & $7(18.42)$ & $7(17.07)$ & \\
\hline High & $0(0.00)$ & $21(55.26)$ & $4(9.76)$ & \\
\hline \multicolumn{5}{|l|}{ Carotenoids, $N(\%)$} \\
\hline None & $4(10.00)$ & $9(23.68)$ & $8(19.51)$ & \multirow{4}{*}{0.31} \\
\hline Low & $17(42.50)$ & $16(42.11)$ & $19(46.34)$ & \\
\hline Intermediate & $19(47.50)$ & $12(31.58)$ & $14(34.15)$ & \\
\hline High & $0(0.00)$ & $1(2.63)$ & $0(0.0)$ & \\
\hline \multicolumn{5}{|l|}{ Astaxanthines, $N(\%)$} \\
\hline None & $15(37.50)$ & $0(0.00)$ & $0(0.00)$ & \multirow{4}{*}{$<0.01$} \\
\hline Low & $16(40.00)$ & $13(34.21)$ & $17(41.46)$ & \\
\hline Intermediate & $8(20.00)$ & $14(36.84)$ & $12(29.27)$ & \\
\hline High & $1(2.50)$ & $11(28.95)$ & $12(29.27)$ & \\
\hline \multicolumn{5}{|l|}{ Polyphenols, N (\%) } \\
\hline None & $17(42.50)$ & $0(0.00)$ & $0(0.00)$ & \multirow{4}{*}{$<0.01$} \\
\hline Low & $18(45.00)$ & $19(50.00)$ & $16(39.02)$ & \\
\hline Intermediate & $4(10.00)$ & $5(13.16)$ & $14(34.15)$ & \\
\hline High & $1(2.50)$ & $14(36.84)$ & $11(26.83)$ & \\
\hline
\end{tabular}

Table 3. Main foods rich in furocumarins consumed by the studied population.

\begin{tabular}{ccccc}
\hline Specific Foods Intake & $\begin{array}{c}\text { Omnivores } \\
(n=40), \mathbf{g} / \text { week }\end{array}$ & $\begin{array}{c}\text { Vegans } \\
(n=38), \mathbf{g} / \text { week }\end{array}$ & $\begin{array}{c}\text { Vegetarians } \\
(n=41), \mathbf{g} / \text { week }\end{array}$ & $p$ \\
\hline Parsley (average (SD) & $1.0(2.8)$ & $601.3(467.4)$ & $35.3(80.0)$ & $<0.001$ \\
\hline Grapefruit (average (SD) & $7.5(26.7)$ & $1611.8(1122.1)$ & $113.9(223.6)$ & $<0.001$ \\
\hline Lime (average (SD) & $2.5(11.0)$ & $277.6(245.3)$ & $38.3(60.9)$ & $<0.001$ \\
\hline Lemon (average (SD) & $5.6(17.4)$ & $960.5(495.0)$ & $34.1(74.5)$ & $<0.001$ \\
\hline Celeriac (average (SD) & $0(0)$ & $717.1(948.3)$ & $67.1(187.6)$ & $<0.001$ \\
\hline Parsnip (average (SD) & $0(0)$ & $1063.2(920.1)$ & $23.2(65.3)$ & $<0.001$ \\
\hline Celery (average (SD) & $3.8(13.3)$ & $1355.3(553.3)$ & $169.5(304.9)$ & $<0.001$ \\
\hline Orange (average (SD) & $13.8(40.8)$ & $1726.3(615.4)$ & $402.2(458.8)$ & $<0.001$ \\
\hline Cilantro (aver-age (SD) & $0.3(1.6)$ & $96.2(145.4)$ & $6.7(13.9)$ & $<0.001$ \\
\hline Carrots (average (SD) & $8.2(33.6)$ & $1815.8(711.1)$ & $525.6(785.4)$ & $<0.001$ \\
\hline
\end{tabular}

\section{Discussion}

Several anecdotal cases had focused on vegetarian diet in humans with discordant results in establishing a potential cause-effect link between furocumarin-rich foods intake and a potential photosensitivity modification, conversely we found that a higher dietary intake of furocumarins in vegan and vegetarian diets is associated with greater skin sensitivity to NB-UVB phototherapy in psoriatic patients. Due to the increased prevalence of vegans and vegetarians among psoriatic patients [35], dermatologists started to evaluate potential differences in clinical outcomes and therapeutic management [36,37]. Although the Mediterranean diet, which is rich in vegetables, is regarded as beneficial for psoriatic patients [1], the impact of the single-food ingredients on phototherapy is entirely unknown. Furthermore, several foods included in the Mediterranean diet, such as celery, parsnip, carrot, parsley, citrus and figs, contain furocumarins, a natural, well-known photosensitizer able to trigger phytophotodermatitis in both humans and animals [20,38]. Since $100 \mathrm{~g}$ of parsnip or celery may contain up to $4-5 \mathrm{mg}$ furocumarins, and a normal US diet only 
$1.3 \mathrm{mg}$ furocumarins per day, a diet rich in some vegetables may contain up to $13 \mathrm{mg}$ per day in the case of vegans and vegetarians, potentially sustaining photosensitivity $[39,40]$.

Thus, our results support the notion that diet has a clinically meaningful impact on phototherapy management in psoriasis patients. In particular, clinicians treating psoriatic patients with phototherapy should include diet information in medical history. Vegans and vegetarians with psoriasis displayed higher photosensitivity than omnivores, and deserve ad hoc phototherapy management [28].

Phototoxicity has been widely proven in UVA wavelengths, since, in this UV range, psoralen DNA monoadducts are efficiently induced, but the greater the quantity ingested with a diet might convert the monoadducts to crosslinks [41,42]. Maximal phototoxic skin reactions in humans are induced by wavelengths between 334 and $425 \mathrm{~nm}$, which perfectly falls into UVA spectrum (320-340 nm); however, in the presence of psoralens, such as furocumarins, phototoxicity may also appear in the spectrum of the less erythematogenic NB-UVB (311-313 nm).

To further empower this statement, small amounts of dietary intake of furocumarins were reported to trigger photoxicity in both PUVA and NB-UVB $[20,36]$.

We found an increased erythemal response to NB-UVB in subjects with high consumptions of furocumarins-rich foods; this is in contrast with Beattie et al., who found no effect when analyzing UVA-related photosensitivity [42].

Our results regarding erythemal response in psoriatic NB-UVB users undergoing different diet regimens and furocumarins intakes could be explained both quantitatively, since vegans and vegetarians consume more food containing furocumarins than omnivores, and qualitatively, since furocumarins bioavailability is affected by storage (fresh vs. frozen) and cooking (fresh vs. cooked) methods [41]. Interestingly, vegans and vegetarians consume foods containing high quantities of both antioxidants (astaxanthines and polyphenols) and furocumarins, but antioxidants may not counteract furocumarins-related photosensitivity/phototoxicity in our cohort of psoriatic patients. It is noteworthy that furocumarins have been shown to induce the secretion of melatonin in humans [43]; melatonin is a known antioxidant and anti-inflammatory hormone that exerts beneficial properties in the skin, and it is lower in psoriatic patients compared to healthy controls [44]. Although melatonin plasma levels were not measured in our cohort, this specific effect by furocumarins on melatonin, coupled with the effect on phototherapy response demonstrated here, may be of interest in the management of disorders, including psoriasis, which is itself associated with abnormalities in circadian rhythms [43].

This pilot study presents limitations, including a small sample size and a lack of skin metabolomic differences between the three considered groups. Furthermore, we used a solar simulator since the monochromator, the most precise instrument to measure MED on the market, was not present in the involved centers [45,46]. As current Italian guidelines did not suggest a specific instrument to measure MED [28], we used a solar simulator that, together with the monochromator, is internationally regarded as the gold standard [28].

\section{Conclusions}

In our study we found a different diet-related effect to NB-UVB, and this aspect acquired paramount importance, since vegans and vegetarians experience more erythema during NB-UVB, thus limiting the total number of phototherapy sessions in the considered period. Dermatologists should consider dietary assessment in patients' clinical evaluation, and eventually also adapt phototherapy protocols to diet characteristics, since they seems to moderately influence patient management and clinical outcomes. Our clinical recommendations are summarized in Table 4.

Further studies warranted to assess the impact of circadian rhythmicity on NB-UVB phototherapy sessions in clinical practice. 
Table 4. Clinical recommendations based on diet for NB-UVB phototherapy in patients with psoriasis.

\begin{tabular}{ll}
\hline NB-UVB CLINICAL RECOMMENDATIONS BASED ON DIET \\
\hline Omnivores & $\begin{array}{l}\text { The starting dose is established after MED evaluation and corresponds to } 70 \% \\
\text { of the MED; then, the dose is increased by } 20 \% \text { (if no erythema) or by } 10 \% \text { (in } \\
\text { case of erythema) up to a maximum dosage of } 3 \mathrm{~J} / \mathrm{cm}^{2}\end{array}$ \\
\hline & $\begin{array}{l}\text { The starting dose is established after MED evaluation and, in case of a low } \\
\text { MED }\left(20-25 \mathrm{~mJ} / \mathrm{cm}^{2}\right), \text { corresponds to } 40 \% \text { of the MED; then, the dose is } \\
\text { increased by } 10 \% \text { if no erythema) up to a maximum single dose of } 2.5 \mathrm{~J} / \mathrm{cm}^{2} .\end{array}$ \\
& In case of erythema the dose is maintained constant
\end{tabular}

MED: minimal erythematous dose.

Author Contributions: Conceptualization, A.P. and G.D.; methodology, R.R.Z.C.; software, R.R.Z.C.; validation, A.P., S.d.G., A.G., E.S. and K.K.; formal analysis, R.R.Z.C. and K.K.; investigation, A.P., A.C., M.A., A.M., P.D.M.P. and G.D.; resources, S.R.F., S.G., E.S., K.K. and G.D.; data curation, R.R.Z.C., S.d.G. and G.D.; writing-original draft preparation, A.P., R.R.Z.C. and G.D.; writingreview and editing, A.P., R.R.Z.C., A.C., S.G., M.A., A.M., P.I., S.d.G., P.D.M.P., A.G., S.R.F., S.G., K.K. and G.D.; visualization, R.R.Z.C. and K.K.; supervision, G.D.; project administration, A.P., A.C. and A.M.; funding acquisition, G.D. All authors have read and agreed to the published version of the manuscript.

Funding: This research received no external funding.

Institutional Review Board Statement: Saint Rafael Hospital (OSR) local ethical committee approved in 28 May 2021 the study protocol 176/int/2020 and the current study represents a posthoc analysis.

Informed Consent Statement: Informed consent was obtained from all subjects involved in the study.

Data Availability Statement: Data available on request due to ethical restrictions. The data presented in this study are available on request from the corresponding author.

Acknowledgments: We thank our data-manger, Ilaria Controne, for her expertise in nutrition.

Conflicts of Interest: The authors declare no conflict of interest.

\section{References}

1. Ben Abdallah, H.; Johansen, C.; Iversen, L. Key Signaling Pathways in Psoriasis: Recent Insights from Antipsoriatic Therapeutics. Psoriasis (Auckland) 2021, 11, 83-97.

2. Marzano, A.V.; Damiani, G.; Genovese, G.; Gattorno, M. A dermatologic perspective on autoinflammatory diseases. Clin. Exp. Rheumatol. 2018, 36 (Suppl. 110), 32-38.

3. Stober, C. Pathogenesis of psoriatic arthritis. Best Pract. Res. Clin. Rheumatol. 2021, 35, 101694. [CrossRef]

4. Yan, D.; Blauvelt, A.; Dey, A.K.; Golpanian, R.S.; Hwang, S.T.; Mehta, N.N.; Myers, B.; Shi, Z.-R.; Yosipovitch, G.; Bell, S.; et al. New Frontiers in Psoriatic Disease Research, Part II: Comorbidities and Targeted Therapies. J. Investig. Dermatol. 2021. [CrossRef] [PubMed]

5. Santus, P.; Rizzi, M.; Radovanovic, D.; Airoldi, A.; Cristiano, A.; Conic, R.; Petrou, S.; Pigatto, P.D.M.; Bragazzi, N.; Colombo, D.; et al. Psoriasis and Respiratory Comorbidities: The Added Value of Fraction of Exhaled Nitric Oxide as a New Method to Detect, Evaluate, and Monitor Psoriatic Systemic Involvement and Therapeutic Efficacy. Biomed Res. Int. 2018, 2018, 3140682. [CrossRef] [PubMed]

6. Damiani, G.; Pacifico, A.; Rizzi, M.; Santus, P.; Bridgewood, C.; Bragazzi, N.; Adawi, M.; Watad, A. Patients with psoriatic arthritis have higher levels of FeNO than those with only psoriasis, which may reflect a higher prevalence of a subclinical respiratory involvement. Clin. Rheumatol. 2020, 39, 2981-2988. [CrossRef] [PubMed]

7. Damiani, G.; Radaeli, A.; Olivini, A.; Calvara-Pinton, P.; Malerba, M. Increased airway inflammation in patients with psoriasis. Br. J. Dermatol. 2016, 175, 797-799. [CrossRef] [PubMed]

8. Malerba, M.; Damiani, G.; Radaeli, A.; Ragnoli, B.; Olivini, A.; Calzavara-Pinton, P. Narrowband ultraviolet B phototherapy in psoriasis reduces proinflammatory cytokine levels and improves vitiligo and neutrophilic asthma. Br. J. Dermatol. 2015, 173, 1544-1545. [CrossRef]

9. Conic, R.R.; Damiani, G.; Schrom, K.P.; Ramser, A.E.; Zheng, C.; Xu, R.; McCormick, T.S.; Cooper, K.D. Psoriasis and Psoriatic Arthritis Cardiovascular Disease Endotypes Identified by Red Blood Cell Distribution Width and Mean Platelet Volume. J. Clin. Med. 2020, 9, 186. [CrossRef]

10. Seth, D.; Ehlert, A.N.; Golden, J.B.; Damiani, G.; McCormick, T.S.; Cameron, M.J.; Cooper, K.D. Interaction of Resistin and Systolic Blood Pressure in Psoriasis Severity. J. Investig. Dermatol. 2020, 140, 1279-1282.e1. [CrossRef] 
11. Barrea, L.; Balato, N.; Di Somma, C.; Macchia, P.E.; Napolitano, M.; Savanelli, M.C.; Esposito, K.; Colao, A.; Savastano, S. Nutrition and psoriasis: Is there any association between the severity of the disease and adherence to the Mediterranean diet? J. Transl. Med. 2015, 13, 18. [CrossRef] [PubMed]

12. Ford, A.R.; Siegel, M.; Bagel, J.; Cordoro, K.M.; Garg, A.; Gottlieb, A.; Green, L.J.; Gudjonsson, J.E.; Koo, J.; Lebwohl, M.; et al. Dietary Recommendations for Adults with Psoriasis or Psoriatic Arthritis from the Medical Board of the National Psoriasis Foundation: A Systematic Review. JAMA Dermatol. 2018, 154, 934-950. [CrossRef]

13. Phan, C.; Touvier, M.; Kesse-Guyot, E.; Adjibade, M.; Hercberg, S.; Wolkenstein, P.; Chosidow, O.; Ezzedine, K.; Sbidian, E. Association between Mediterranean Anti-inflammatory Dietary Profile and Severity of Psoriasis: Results from the NutriNet-Santé Cohort. JAMA Dermatol. 2018, 154, 1017-1024. [CrossRef]

14. Adawi, M.; Damiani, G.; Bragazzi, N.L.; Bridgewood, C.; Pacifico, A.; Conic, R.R.; Morrone, A.; Malagoli, P.; Pigatto, P.D.M.; Amital, H.; et al. The Impact of Intermittent Fasting (Ramadan Fasting) on Psoriatic Arthritis Disease Activity, Enthesitis, and Dactylitis: A Multicentre Study. Nutrients 2019, 11, 601. [CrossRef] [PubMed]

15. Damiani, G.; Watad, A.; Bridgewood, C.; Pigatto, P.D.M.; Pacifico, A.; Malagoli, P.; Bragazzi, N.L.; Adawi, M. The Impact of Ramadan Fasting on the Reduction of PASI Score, in Moderate-To-Severe Psoriatic Patients: A Real-Life Multicenter Study. Nutrients 2019, 11, 277. [CrossRef]

16. Kocic, H.; Damiani, G.; Stamenkovic, B.; Tirant, M.; Jovic, A.; Tiodorovic, D.; Peris, K. Dietary compounds as potential modulators of microRNA expression in psoriasis. Ther. Adv. Chronic Dis. 2019, 10, 2040622319864805. [CrossRef] [PubMed]

17. Damiani, G.; Bragazzi, N.L.; McCormick, T.S.; Pigatto, P.D.M.; Leone, S.; Pacifico, A.; Tiodorovic, D.; Di Franco, S.; Alfieri, A.; Fiore, M. Gut microbiota and nutrient interactions with skin in psoriasis: A comprehensive review of animal and human studies. World J. Clin. Cases 2020, 8, 1002-1012. [CrossRef]

18. Melough, M.M.; Chun, O.K. Dietary furocoumarins and skin cancer: A review of current biological evidence. Food Chem. Toxicol. 2018, 122, 163-171. [CrossRef]

19. Melough, M.M.; Cho, E.; Chun, O.K. Furocoumarins: A review of biochemical activities, dietary sources and intake, and potential health risks. Food Chem. Toxicol. 2018, 113, 99-107. [CrossRef]

20. Boffa, M.J.; Gilmour, E.; Ead, R.D. Celery soup causing severe phototoxicity during PUVAtherapy. Br. J. Dermatol. 1996, $135,334$. [CrossRef] [PubMed]

21. Pacifico, A.; Damiani, G.; Iacovelli, P.; Conic, R.R.; Scarabello, A.; Filoni, A.; Malagoli, P.; Bragazzi, N.; Pigatto, P.D.; Morrone, A. Photoadaptation to ultraviolet B TL01 in psoriatic patients. J. Eur. Acad. Dermatol. Venereol. 2020, 34, 1750-1754. [CrossRef]

22. Addison, R.; Weatherhead, S.C.; Pawitri, A.; Smith, G.R.; Rider, A.; Grantham, H.J.; Cockell, S.J.; Reynolds, N.J. Therapeutic wavelengths of ultraviolet $\mathrm{B}$ radiation activate apoptotic, circadian rhythm, redox signalling and key canonical pathways in psoriatic epidermis. Redox Biol. 2021, 41, 101924. [CrossRef] [PubMed]

23. Ando, N.; Nakamura, Y.; Aoki, R.; Ishimaru, K.; Ogawa, H.; Okumura, K.; Shibata, S.; Shimada, S.; Nakao, A. Circadian Gene Clock Regulates Psoriasis-Like Skin Inflammation in Mice. J. Investig. Dermatol. 2015, 135, 3001-3008. [CrossRef]

24. Rezzani, R.; Rodella, L.F.; Favero, G.; Damiani, G.; Paganelli, C.; Reiter, R.J. Attenuation of ultraviolet A-induced alterations in NIH3T3 dermal fibroblasts by melatonin. Br. J. Dermatol. 2014, 170, 382-391. [CrossRef] [PubMed]

25. Damiani, G.; Bragazzi, N.L.; Garbarino, S.; Chattu, V.K.; Shapiro, C.M.; Pacifico, A.; Malagoli, P.; Pigatto, P.D.M.; Conic, R.R.Z.; Tiodorovic, D.; et al. Psoriatic and psoriatic arthritis patients with and without jet-lag: Does it matter for disease severity scores? Insights and implications from a pilot, prospective study. Chronobiol. Int. 2019, 36, 1733-1740. [CrossRef]

26. Duszka, K.; Wahli, W. Peroxisome Proliferator-Activated Receptors as Molecular Links between Caloric Restriction and Circadian Rhythm. Nutrients 2020, 12, 3476. [CrossRef] [PubMed]

27. Martínez-Lozano, N.; Tvarijonaviciute, A.; Ríos, R.; Barón, I.; Scheer, F.; Garaulet, M. Late Eating Is Associated with Obesity, Inflammatory Markers and Circadian-Related Disturbances in School-Aged Children. Nutrients 2020, 12, 2881. [CrossRef] [PubMed]

28. Russo, F.; Vispi, M.; Sirna, R.; Mancini, V.; Bagnoni, G.; Bartoli, L.; Bellini, M.; Brandini, L.; Caproni, M.; Castelli, A.; et al. Tuscan consensus on the use of UVBnb phototherapy in the treatment of psoriasis. G. Ital. Dermatol. Venereol. 2019, 154, 99-105. [CrossRef]

29. The Vegan Society. So What Do Vegans Eat? Available online: www.vegansociety.com/go-vegan/definition-veganism (accessed on 28 June 2021).

30. Jaacks, L.M.; Kapoor, D.; Singh, K.; Narayan, K.V.; Ali, M.K.; Kadir, M.M.; Mohan, V.; Tandon, N.; Prabhakaran, D. Vegetarianism and cardio- metabolic disease risk factors: Differences between South Asian and US adults. Nutrition 2016, 32, 975-984. [CrossRef]

31. Phenol-Explorer. Database on Polyphenol Content in Foods. Available online: http:// phenol-explorer.eu/foods (accessed on 18 August 2021).

32. Food Science Graz. Available online: https:/ / foodscience.tugraz.at (accessed on 18 August 2021).

33. Fernández-García, E.; Carvajal-Lérida, I.; Jarén-Galán, M.; Garrido-Fernández, J.; Pérez-Gálvez, A.; Hornero-Méndez, D. Carotenoids bioavailability from foods: From plant pigments to efficient biological activities. Food Res. Int. 2012, 46, 438-450. [CrossRef]

34. Fernández-García, E.; Carvajal-Lérida, I.; Jarén-Galán, M.; Garrido-Fernández, J.; Pérez-Gálvez, A.; Hornero-Méndez, D. Identification and Quantitation of Furocoumarins in Popularly Consumed Foods in the U.S. Using QuEChERS Extraction Coupled with UPLC-MS/MS Analysis. J. Agric. Food Chem. 2017, 65, 5049-5055. 
35. Afifi, L.; Danesh, M.J.; Lee, K.M.; Beroukhim, K.; Farahnik, B.; Ahn, R.S.; Yan, D.; Singh, R.K.; Nakamura, M.; Koo, J.; et al. Dietary Behaviors in Psoriasis: Patient-Reported Outcomes from a U.S. National Survey. Dermatol. Ther. 2017, 7, 227-242. [CrossRef] [PubMed]

36. Fusano, M.; Fusano, I.; Galimberti, M.G.; Bencini, M.; Bencini, P.L. Comparison of Postsurgical Scars between Vegan and Omnivore Patients. Dermatol. Surg. 2020, 46, 1572-1576. [CrossRef] [PubMed]

37. Fusano, M.; Zane, C.; Calzavara-Pinton, P.; Bencini, P.L. Photodynamic therapy for actinic keratosis in vegan and omnivore patients: The role of diet on skin healing. J. Dermatolog. Treat. 2019, 32, 78-83. [CrossRef]

38. Puig, L.; de Moragas, J.M. Enhancement of PUVA phototoxic effects following celery ingestion: Cool broth also can burn. Arch. Dermatol. 1994, 130, 809-810. [CrossRef]

39. Wolters, M. Die Bedeutung der Ernährung und begleitender Faktoren für die Psoriasis [The significance of diet and associated factors in psoriasis]. Hautarzt 2006, 57, 999-1004. [CrossRef]

40. Wagstaff, D.J. Dietary exposure to furocumarins. Regul. Toxicol. Pharmacol. 1991, 14, 261-272. [CrossRef]

41. Ortiz-Rodríguez, L.A.; Reichardt, C.; Hoehn, S.J.; Jockusch, S.; Crespo-Hernández, C.E. Detection of the thietane precursor in the UVA formation of the DNA 6-4 photoadduct. Nat. Commun. 2020, 11, 3599. [CrossRef]

42. Beattie, P.E.; Wilkie, M.J.V.; Smith, G.; Ferguson, J.; Ibbottson, S.H. Can dietary furocumarin ingestion enhance the erythemal response during high dose UVA1 therapy? J. Am. Acad. Dermatol. 2007, 56, 84-87. [CrossRef]

43. Souetre, E.; Salvati, E.; Belugou, J.L.; Krebs, B.; Darcourt, G. 5-Methoxypsoralen as a specific stimulating agent of melatonin secretion in humans. J. Clin. Endocrinol. Metab. 1990, 71, 670-674. [CrossRef]

44. Mozzanica, N.; Tadini, G.; Radaelli, A.; Negri, M.; Pigatto, P.; Morelli, M.; Frigerio, U.; Finzi, A.; Esposti, G.; Rossi, D. Plasma melatonin levels in psoriasis. Acta Derm.-Venereol. 1988, 68, 312-316. [PubMed]

45. Mackenzi, L.A.; Frainbel, W. Construction and Development of a Grating Monochromator and Its Application to Study of Reaction of Skin to Light. Br. J. Dermatol. 1973, 89, 251-264. [CrossRef] [PubMed]

46. Moseley, H.; Ferguson, J. Which light source should be used for the investigation of clinical phototoxicity: Monochromator or solar simulator? Photodermatol. Photoimmunol. Photomed. 2010, 26, 3-6. [CrossRef] [PubMed] 